\title{
Research on Architecture of Knowledge System of Emergency Management
}

\author{
Chunjuan Li \\ College of Economics and Management \\ Yanshan University \\ Hebei,China,066004 \\ e-mail: lcj0321@ysu.edu.cn
}

\begin{abstract}
The management of emergencies, no matter resulting from natural or man-made disasters, requires enough information as well as knowledge. Knowledge management is an important foundation and support for integrating emergency department, optimizing the distribution of emergency resources, sharing emergency information and improving the level of emergency decisions. In order to support the decision-makers to improve the management of the disaster emergencies, knowledge system is good candidates. Firstly, this paper analyzes the causes of the needs of knowledge management and proposes the concept of knowledge system of emergency management (KSEM). Then, according to system engineering, the paper presents the architecture of KSEM which included three subsystems: knowledge subsystem, knowledge body subsystem and material carrier subsystem. Lastly the paper analyzes the relationship between three subsystems. Research on the architecture of KSEM may help emergency management departments systematically managed knowledge and provide the important theoretical basis for developing information technologies. The authors hope the performance of emergency management would be improved in the country and the losses caused by emergencies like disasters would be reduced to a lower degree.
\end{abstract}

Keywords- Knowledge management; Knowledge System; Emergency management

\section{INTRODUCTION}

The experience of the " 7.12 " Beijing torrential rain, "8.26" serious traffic accident and Yunnan earthquake happened during this year in China shows that disasters continue to cause loss of human life, environmental damage, disruption of infrastructure and economic loss. Focusing and researching on emergency management traces back to SARS in 2003. The appearance of SARS situation has exposed the question of the ability of emergency management more definitely at that time. Researching on emergency management has become an important science field during 10 more years.

Now researching on emergency management is a multidisciplinary field and involves many science theories, such as management science, system engineering, behavioral science and calamity science.

The theory and experience of knowledge management are derived from the 1980s. The theories and technical methods of knowledge management provide a new idea to the research of emergency management. Benoit Robert (1996) developed a module for training in environmental emergency response. The module is comprised of three distinct knowledge bases. [1] Josefa Z. Hernandez (2001) proposed the use of advanced knowledge models to support environmental emergency management. [2] Chua Alton Y.K. (2007) presented 14 major delay causes in Katrina. [3] The extent to which the delay causes were a result of the lapses in knowledge management processes.

The content of this paper starts with the analysis of why emergency management needs knowledge management. Next, the identification of knowledge of emergency management is presented. Then, the architecture of knowledge-based system is proposed. Lastly, the architecture of KSEM is described.

\section{DEMAND OF KNOWLEDGE MANAGEMENT FOR EMERGENCY MANAGEMENT}

\section{A. Characteristics of the emergency}

The emergency is not limited to a certain kind of event. Four emergency types are listed as: Natural hazard, Great accidents, Man-made disasters and Epidemics. [4] These emergencies have several distinctive features: 1) uncertainty of occurrence: the emergency may be happened in any time and in any place. 2) complexity of growth: the emergency may vary from hour to hour. 3) destructive effect: the emergency may cause loss of human life, environmental damage, disruption of infrastructure and economic loss. 4) lose effectiveness of formal management methods: emergency management is different with formal management. The process of mitigation, preparedness, response and recovery involves knowledge from different science fields.

\section{B. Collaboration in emergency management}

As to emergency management, it means to intervene and control emergencies with scientific methods during the whole period, including mitigation, preparedness, response and recovery so as to minimize the loss. [5] Facing the complicated and dramatically changing environment, several emergency management departments have grouped together and worked collaboratively. The decision-makers make response plan through analysis of enormous information from the scenes. It is very important that proper knowledge was sent to proper people within proper time. Nevertheless, very few rescue departments has same 
knowledge structure and experience. Undoubtedly, it will very difficult to communicate properly for them.

\section{Insufficiency in emergency knowledge}

Some organizations hold that emergencies are lowfrequency events, thus opportunities are not enough to learn crises and to study how to cope with them. Therefore, knowledge gap exists in organizations, including crisis prevention knowledge, knowledge related to rescues after the happening of crisis, restoration knowledge and some other knowledge.

Take fire for instance, there is no authoritative operation rules and regulations in dividing scene warning area as well as the standard of restoration of the scene after rescue. Some countries, including Britain, Japan and Russia, have made an effort to strengthen the data management in city fundamental information. If some major emergencies occurred, such as earthquakes, fire and terrorist attacks, the degree and the general number of casualties can be assessed and the damage assessment report can be worked out within 24 hours. [6] This is exceedingly helpful to the implementation of the decision on rescue in time.

\section{KNOWLEDGE AND KNOWLEDGE BODIES IN KSEM}

The emergency management is a complex system which is comprised of a number of organizations and people that were connected with kinds of networks. The KSEM is a kind of knowledge system composed of knowledge and knowledge actions which were identified, achieved and shared in the process of emergency management.

\section{A. Knowledge in KSEM}

Most definitions of knowledge focus on some combination of the following: know-what, know-why, knowhow, know-who; know-where; know-which, know-when, etc. (OECD 1996). Polanyi(1966)divides knowledge into two types: explicit and tacit. Josefa Z. Hernandez (2001) proposed three knowledge components as incident identification knowledge, impact estimation knowledge, emergency actions knowledge. This paper defines that emergency knowledge was a collection of explicit knowledge and tacit knowledge gained, transformed and shared in the whole process of emergency management.

Because of the intangibility of knowledge, it has to depend on some certain material media to stock and exchange, which are named knowledge carriers. The knowledge carriers in emergency management can be classified into three categories. The first one is documented paper carrier mainly including emergency plans, technical documents, emergency case base, laws and regulations. The second one is a computer system stocking knowledge through computer electronic files, state base and some other ways. An emergency management information system should be set up to spread information. Knowledge can be created by analyzing and digging data to instruct practice and to improve emergency decisions under emergency. The third one is human brain or sense of community, i.e. the carrier of tacit knowledge. They consist of a great amount of knowledge obtained from professional work, working experience and collaborative ability by emergency experts and emergency teams. Table 1 lists the main knowledge activities and carriers in each stage of emergency management.

\begin{tabular}{|c|c|c|}
\hline TABLE I. & \multicolumn{2}{|c|}{$\begin{array}{l}\text { MAIN KNOWLEDGE ACTIVITIES AND CARRIERS IN EACH } \\
\text { STAGE OF EMERGENCY MANAGEMENT }\end{array}$} \\
\hline $\begin{array}{l}\text { Stages of } \\
\text { emergency }\end{array}$ & Major knowledge activities & $\begin{array}{l}\text { Knowledge } \\
\text { carriers }\end{array}$ \\
\hline Prevention & $\begin{array}{l}\text { Risk alert knowledge(collecting, } \\
\text { monitoring and }\end{array} \quad \begin{array}{r}\text { releasing } \\
\text { information), crisis } \\
\text { knowention } \\
\text { etc.) }\end{array}$ & \multirow{4}{*}{$\begin{array}{l}\text { Emergency } \\
\text { plans, } \\
\text { Technical } \\
\text { files, } \\
\text { Emergency } \\
\text { case base, } \\
\text { Laws and } \\
\text { regulations, } \\
\text { EM } \\
\text { information } \\
\text { system, } \\
\text { Emergency } \\
\text { experts or } \\
\text { organi } \\
\text { zations }\end{array}$} \\
\hline Preparation & $\begin{array}{l}\text { knowledge of establishing } \\
\text { organizations } \\
\text { (e.g. professional rescue team, } \\
\text { emergency command center), } \\
\text { training knowledge(emergency } \\
\text { drills and technical } \\
\text { training),knowledge of drafting } \\
\text { plans and managing resources for } \\
\text { emergencies(e.g. material resources } \\
\text { and funds) }\end{array}$ & \\
\hline Response & $\begin{array}{l}\text { emergency demand, dispatching } \\
\text { resources, rescue knowledge and } \\
\text { knowledge on coordination and } \\
\text { communication }\end{array}$ & \\
\hline Recovery & $\begin{array}{lcr}\text { knowledge } & \text { of } & \text { restoration, } \\
\text { prevention } & \text { of } & \text { diseases, } \\
\text { psychological intervention and post- } \\
\text { disaster } & \text { assessment(damage } \\
\text { assessment and summarizing } \\
\text { experience) }\end{array}$ & \\
\hline
\end{tabular}

\section{B. Knowledge bodies in KSEM}

The body of KSEM mainly points people and departments in emergency management. According to various assignments in emergency management, there are four types of knowledge bodies:

- Decision-maker. Decision-maker in emergency management called emergency management office or emergency management center as well which is composed of local or national government departments and senior experts or consultants. Decision-makers pay an important role in KSEM. They draw up pre-arranged planning, work out rescue action plan, share enormous information and keep connection with other participants, along with a large number of knowledge and knowledge flow.

- Participant. The main participants in emergency management are the police, fire department, hospitals, communication department, etc. The participants own much professional knowledge, such as rescue knowledge, organization knowledge, collaboration knowledge, which is necessary to make decision in KSEM. They communicate with decision-maker and take part in rescue in the process of emergency management.

- Sources supplier. A large number of sources including goods and materials are needed in the process of emergency management. Many companies and organization participate in. Decision- 
makers transmit information about the type and quantity of sources to suppliers and decide when or where sources send to.

- Media and the public. When the emergencies happened, information from the scene should spread to the public except rescue work. The public need to know what happened in first time. If the report was delayed, the circulation of gossip will spread out and social stability may be affected. [7] Therefore, the media is responsible for report information from the scene correctly and timely.

\section{ARCHITECTURE FOR KSEM}

The architecture of system is used to describe the structure of system and composition of modules. It usually puts particular emphasis on the principle and structure not technological details. The paper analyzed the cause of knowledge management for emergency management and listed knowledge body and knowledge activities in emergency management in two chapters preceded. It was laid foundations for architecting of KSEM.

According to the theory of science engineering, knowledge-based system can be divided into three subsystems: 1) knowledge subsystem (composed of knowledge and connections between it) 2) knowledge body subsystem (composed of people and organizations and relationship between them) 3) goods and materials carrier subsystem (composed of paper or electronic documents). The architecture of the description of the relationship between three subsystems is shown in Fig.1.

Drawing on architecture of KSEM, emergency management departments can systematically manage knowledge, develop information technologies and research the methods used in KSEM next. Further steps in this direction will focus on simulation of the system and operation of it. [8] We hope the efficiency of emergency management can be greatly improved in our country and the losses caused by emergencies like disasters would be reduced for higher degree.

\section{A. The connection of knowledge bodies in KSEM}

Knowledge body subsystem of KSEM is composed of knowledge bodies and the connection between them. The relationships of four types of knowledge bodies hereinbefore constitute a kind of social network in which knowledge bodies are nodes and the connection of bodies are edges. The connections of knowledge present multi-direction and multiform complex network among the whole knowledge management process from knowledge exchanging and training in normal to knowledge sharing and collaboration when emergencies happened. In emergent time, the construction of knowledge body network can make clear of the deliver and flow path of knowledge. In order to accelerate the speed of knowledge spread and improve the connectivity of people network, the SOA theory can be used in calculate the in-degree and out-degree of the main nodes and the length of path connected nodes in knowledge body network.



Fig. 1 Architecture of KSEM

B. The connection of knowledge in knowledge subsystem

Knowledge subsystem of KSEM is composed of knowledge and the connection between it. Using and managing knowledge usually represent the flow of knowledge. In the process of emergency management, the departments depend on large amount of knowledge to make correct decision. The process of knowledge includes the knowledge acquisition, knowledge storage and knowledge sharing. This process of knowledge is closely related to the process of emergency management. Figure 2 shows two circle models. One is the circle of process of emergency management including emergency prevention, emergency preparation, emergency response and emergency recovery. The process of emergency management is accompanied by the flow of knowledge which also showed the circle type. It is worthwhile to note that both circles were not simultaneous. There is not a one-to-one relationship between the links in emergency process and knowledge process. The circle of knowledge process will include more complex knowledge flow in practice.

\section{The support subsystem of KSEM}

The support subsystem of KSEM includes technical platform, knowledge bases and databases. The databases consist of basis information data and professional data of cities or regions. The basis information data contain administrative divisions, populations, geographic information, infrastructures, refuges and sources of hazard, 


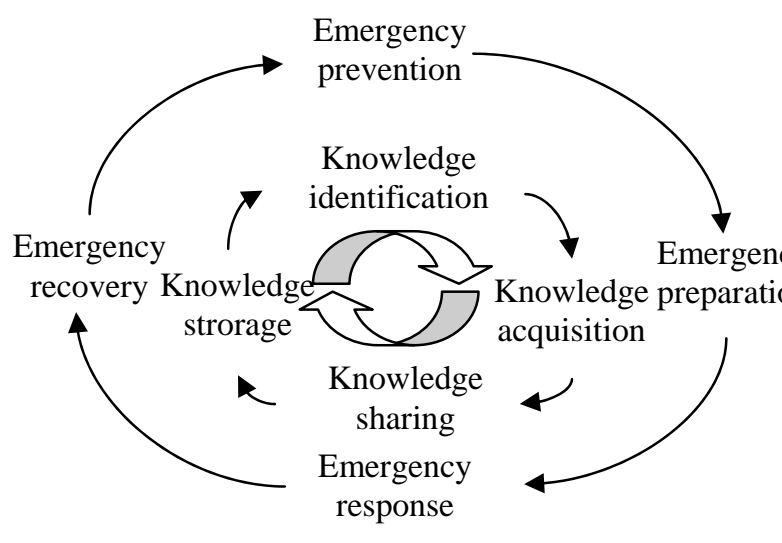

Fig.2 Relationship between emergency process and knowledge process

etc. These basis data is very important to emergency rescue. It is seemed simple but needed long-term investigation and statistic. The professional data is provided by the emergency departments, for instance, the police, fire department, hospitals and communities. The knowledge base is an "intelligence base" of EM which stored knowledge from learning, accumulation and summaries in emergency practices. The knowledge bases consist of emergency response plan, examples of emergencies case, emergency law and emergency experts. The technical platform is conductive to knowledge delivering and sharing. As a result of the isomerism of information system databases in different departments, it is a necessity to set up corresponding software interfaces for knowledge management system to share information resources in other systems. Corresponding technologies include XML technology, Agent technology, DCOM technology, distributive database technology and some other relative technologies. Technologies above are used to set the technology and standard of sharing information when information system integrating.

\section{Relationship between three subsystems}

Knowledge of knowledge subsystem comes from which knowledge body subsystem and support subsystem obtain, share and store. Knowledge subsystem is a kind of virtual system. Knowledge of knowledge subsystem is dynamic mapping of two other subsystems. And knowledge body subsystem and support subsystem is vehicle of knowledge. Knowledge body subsystem is in dominant position in three subsystems. The changes of internal composition or connection in body subsystem will directly influence the other subsystems.

\section{CONCLUSION}

With the rapid development of economy and the acceleration of urbanization in China and the deterioration of the environment in the world, various emergency public events have been increasingly frequent. To improve the level of emergency management is an urgent need of the application and research of emergency management. With the help of the theories and methods of knowledge management and system engineering, this paper proposes the concept of knowledge system of emergency management (KSEM), presents the architecture of KSEM which included three subsystems: knowledge subsystem, knowledge body subsystem and material carrier subsystem and analyzes the relationship between three subsystems.

Drawing on architecture of KSEM, emergency management departments can systematically manage knowledge, develop information technologies and research the methods used in KSEM next. Further steps in this direction will focus on simulation of the system and operation of it. The authors hope the efficiency of emergency management can be greatly improved in our country and the losses caused by emergencies like disasters would be reduced to a lower degree.

\section{REFERENCES}

[1] Benoit Robert, Chantal Gamelin, Rober Hausler and Vincent Jarry, "Training concept for environmental emergency measures: Structuring knowledge," Journal of Contingencies and Crisis Management,vol. 4,Sep.1996,pp. 175-183.

[2] Josefa Z. HernaÂndez, Juan M. Serrano, "Knowledge-based models for emergency management systems," Expert Systems with Applications, vol. 20,Feb. 2001,pp. 173-186.

[3] Chua, Alton Y. K., Kaynak, Selcan, Foo, Schubert S. B, “An analysis of the delayed response to Hurricane Katrina through the lens of knowledge management," Journal of the American Society for Information Science Technology, vol.58, Feb.2007, pp. 391-403.

[4] Nezih Altay, Walter G. Green, "OR/MS research in disaster operations management,”. European Journal of Operational Research, vol.175,Nov.2006,pp.475-493.

[5] Anklam Patti,. "Knowledge management: the collaboration thread," Bulletin of the American Society for Information Science and Technology, vol. 28, Jue. 2002,pp.8-11.

[6] Rui Chen, H Raghav Rao, Raj Sharman, Shambhu J Upadhyaya, Jinki Kim, "An empirical examination of IT-enabled emergency response: The cases of Hurricane Katrina and Hurricane Rita," Communications of the Association for Information Systems,vol.26, Mar. 2010, pp.141-156.

[7] Robert L. Heath, Jaesub Lee, Lan Ni, "Crisis and risk approaches to emergency management planning and communication: The role of similarity and sensitivity," Journal of Public Relations Research,vol.21, Feb. 2009, pp.123-141.

[8] Zhenliang Liao, Bo Wang, Xiaowei Xia, Phillip M. Hannam, "Environmental emergency decision support system based on Artificial Neural Network,” Safety Science, vol.50, Jan.2012, pp.150163. 